\title{
Total cholesterol concentration predicts the effect of plasmapheresis on hypertriglyceridemic acute pancreatitis: a retrospective case-control study
}

\author{
Zhu Chen ${ }^{1+}$, Xiaolong Huang ${ }^{1+}, \mathrm{Na} \mathrm{Han}^{2+}$, Yanxia Guo $^{1}$, Jing Chen ${ }^{1}$, Yaogui Ning ${ }^{1}$ and Minwei Zhang ${ }^{1 *}$
}

\begin{abstract}
Background: What kind of patients with hypertriglyceridemic acute pancreatitis (HLAP) might benefit from plasmapheresis (PP) remains unknown. The objective of this study is to determine the predict function of total cholesterol (TC) on the Triglyceride (TG)-lowing effect in patients on either non-PP or PP therapy.
\end{abstract}

Methods: Patients were categorized into high total cholesterol (HTC)/low total cholesterol (LTC) groups based on TC level of $12.4 \mathrm{mmol} / \mathrm{L}$. The primary outcome was TG reduction to below $500 \mathrm{mg} / \mathrm{dL}$ within $48 \mathrm{~h}$. Linear mixed-effect model and logistic regression analyses were used to assess the association of TC level and TG-lowing efficacy in different therapy groups.

Results: Compared with LTC group, patients with HTC showed more severe imaging manifestations $(p<0.001)$ and higher APACH II scores $(p=0.036)$. Deaths occurred only in HTC groups. Significant interaction of time sequence with the 2 TGs-lowing therapy groups on TG level was only found in HTC group $(p<0.001)$. In patients with elevated TC level, primary outcome occurred in $66.67 \%$ of patients in the PP group, and $27.91 \%$ in the non-PP group. After adjustment for age, gender, CT grade and APACH II score, the odd ratio remain significant (OR 5.47, 95\% confidence interval $[\mathrm{Cl}] 1.84-16.25, p=0.002$ ). Furthermore, in patients with lower TC level, no significant difference was found in primary outcome between PP group and non-PP group (81.25\% versus 62.30\%, adjusted OR 2.05; 95\% Cl 0.45-9.40; $p=0.353$ ).

Conclusions: TC could be a potential biomarker to predict the effects of TG-lowing therapy in patients with HLAP.

Keywords: Total cholesterol, Plasmapheresis, Effectiveness, Hypertriglyceridemia, Acute pancreatitis

\section{Background}

Acute pancreatitis (AP) is a clinically common lifethreatening disease, and its incidence is increasing worldwide [1]. Hypertriglyceridemia is the third most common cause of AP after the gallstones (up to 60\%)

\footnotetext{
*Correspondence: zmwicu2019@sina.com

${ }^{\dagger}$ Zhu Chen, Xiaolong Huang and Na Han contributed equally to this work ${ }^{1}$ Intensive Care Unit, The First Affiliated Hospital of Xiamen University, NO. 55, Zhenhai Road, Siming District, Xiamen City, Fujian 361003, People's Republic of China

Full list of author information is available at the end of the article
}

and alcohol (30\%), accounting for nearly $10 \%$ of all cases. More importantly, there may be a dose-response relationship between hypertriglyceridemia and the severity and complications of AP [2]. The incidence of hypertriglyceridemic acute pancreatitis (HLAP) is gradually increasing [3, 4], and its associated mortality can exceed $30 \%[5]$.

Basic treatments for HLAP are strict restrictions regarding oral fasting, fluid resuscitation and analgesia. Beyond that, plasmapheresis (PP) has also been recommended for the treatment of HLAP due to its rapid 
removal of abnormal substances from patients' blood [6, 7].

At present, the clinical efficacy of PP for patients with HLAP is still unclear and controversial. Some studies report that PP can remove triglycerides (TGs) and chylomicron from circulation drastically within hours [8], while a recent retrospective study found that PP therapy had no additional TG-lowering effects [9] What's more, many studies have found that PP does not reduce mortality rates among patients with HLAP $[10,11]$. In addition, PP requires special treatment equipment, is expensive, and involves some risks, such as allergy, bleeding and infection [12].

The vast heterogeneity of the underlying clinical scenarios of patients with HLAP partly leads to TG-lowering treatment failure. Therefore, identifying the patients who are more suitable for PP treatment is important, but few relevant studies have been published. Total cholesterol (TC) can act as an early predictor of persistent organ failure and mortality in patients with AP [13, 14]. Additionally, TC are favorable predictors of the development of severe acute pancreatitis (SAP) in patients with AP [15]. Accordingly, we propose that TC levels might be useful to predict patients' response to PP therapy.

\section{Methods}

This retrospective case-control study was approved by the institutional review board of the first affiliated hospital of Xiamen University.

\section{Patients}

Between January 2013 and December 2018, 1772 patients were diagnosed with pancreatitis and received treatment at the first affiliated hospital of Xiamen University. (Xiamen, China). In order to avoid selection bias as much as possible, we continuously included patients of 5 years. A total of 150 patients were diagnosed with HLAP and included in this retrospective case-control study. 46 patients were treated with PP and 104 patients were not. HLAP was diagnosed using the Atlanta Classification criteria [3]. The inclusion criteria were as follows: (1) TGs $>1000 \mathrm{mg} / \mathrm{dL}$; (2) the occurrence of two in the following three factors: typical abdominal pain, pancreatic enzymes exceeding the normal upper limit by more than 3 times, and radiological findings of AP [16]; (3) age of 18 years or older. We excluded pregnant women with HLAP and patients with other causative conditions, such as alcohol, gall stones, trauma or neoplasm.

\section{Treatment}

The initial treatment of HLAP, as with other causes of pancreatitis, includes intestinal rest, fasting, intravenous fluids and pain relief. PP will be performed as soon as possible within $24 \mathrm{~h}$ after admission to ICU because of severe AP when the patient's TG level was higher than $1000 \mathrm{mg} / \mathrm{dL}$ and informed consent. The PP sessions were performed using the Aquarius system (Edwards Lifesciences LLC, One Edwards Way, Irvine, USA) and the Plasmaflo TPE op-08w filter (Asahi KASEI Medical Co., Ltd, Yurakucho, Chiyoda-ku, Tokyo). In general, approximately $3 \mathrm{~L}$ of plasma were exchanged at a time, and the treatments lasted approximately $3 \mathrm{~h}$. During PP, heparin $(500 \mathrm{U} / \mathrm{h})$ was continuously pumped before the filter, and calcium $(1 \mathrm{~g} / \mathrm{h})$ was added after the filter. PP was performed once a day until TG levels were below $1000 \mathrm{mg} /$ dL.

\section{Outcome}

The primary efficacy outcome was TGs $<500 \mathrm{mg} / \mathrm{dL}$ within $48 \mathrm{~h}$ of admission [17]. The secondary efficacy outcome included the change in serum TG concentrations within $72 \mathrm{~h}$ of admission.

\section{Data collection}

Demographic, clinical, and laboratory data were collected on the day of admission. Demographic data included age, sex and body mass index (BMI). Clinical variables included hypertension, diabetes mellitus and diabetic ketosis, hyperuricemia and medical history of pancreatitis. Baseline levels of TC, HDL-C, LDL-C, prealbumin, albumin, serum calcium, C-reactive protein, amylase and lipase were also collected within $24 \mathrm{~h}$ of admission. The time course of serum TG concentration (at baseline, $24 \mathrm{~h}, 48 \mathrm{~h}$ and $72 \mathrm{~h}$ ) was involved in the results analysis. The severity of HLAP was assessed by the Ranson score, the APACHE II score, the Balthazar CT grade and organ function [18]. We simultaneously collected data regarding medical treatment for hypertriglyceridemia (insulin/ heparin), complications or comorbidities of HLAP, length of hospitalization, hospital charges, and mortality at 28 days and 90 days.

\section{Statistical analysis}

Statistical analyses were performed using $\mathrm{R}$ for Windows (version 3.4.2, http://www.r-project.org/). The data are presented as the median (interquartile range) or number (\%). Patients were categorized into high total cholesterol (HTC) /low total cholesterol (LTC) groups based on a TC level of $12.4 \mathrm{mmol} / \mathrm{L}$ (2 times the 'high' limit of total cholesterol based on the recommendations of the National Heart, Lung, and Blood Institute (NHLBI) of the United States [19]). Categorical variables were compared by chi-square/Fisher's exact tests. Because of skewed distribution, continuous variables were compared by the Mann-Whitney U test. For LTC and HTC group, the difference between PP and non-PP therapy in the rates of 
$\mathrm{TG}<500 \mathrm{mg} / \mathrm{dL}$ within $48 \mathrm{~h}$ of admission was analyzed by using univariate and multivariate logistic regression analyses. We included predictors with a $p$ value $<0.1$ from univariate analysis into the backward stepwise multivariate regression with the Akaike Information Criterion (AIC). Treatment group (PP group and non-PP group)time sequence interactions were assessed using the linear mixed-effect model according to repeated measures of TGs. After classifying the patients into four groups based on TC and TG-lowing therapy, we used Fisher's exact tests and Kruskal-Wallis test to compare categorical and continuous variables. $p$ value were adjusted by Bonferroni correction for multiple comparisons among the defined groups. A 2 -sided $p$ value of less than 0.05 was considered to indicate statistical significance.

\section{Results}

Patient characteristics

A total of 150 patients were included in this study. 46 patients received therapeutic PP, and 104 patients did not. The baseline clinical characteristics are listed in Table 1. The median age was 38 years. Most of the patients were male $(78.67 \%)$ and had a high BMI (median 26.15; IQR 24.20-28.30). 39.33\% of the patients had history of pancreatitis. The median plasma levels of TGs and TC were $1760.2 \mathrm{mg} / \mathrm{dL}$ and $12.28 \mathrm{mmol} / \mathrm{L}$, respectively. More than half (51.33\%) of the patients showed more fluid leakage on imaging (Balthazar CT grade: $\mathrm{D} / \mathrm{E}$ ). Organ dysfunction occurred in $20 \%$ of all patients. $67.3 \%$ and $56.0 \%$ patients were treated with insulin and heparin for reducing plasma TGs, respectively. A total of four

Table 1 Baseline clinical characteristics

\begin{tabular}{|c|c|c|c|c|}
\hline & All $(n=150)$ & $\begin{array}{l}\text { LTC group } \\
\text { (cholesterol } \leq 12.40 \mathrm{mmol} / \mathrm{L} \text {, } \\
\mathrm{n}=77 \text { ) }\end{array}$ & $\begin{array}{l}\text { HTC group } \\
\text { (cholesterol > } 12.40 \mathrm{mmol} / \mathrm{L} \text {, } \\
n=73 \text { ) }\end{array}$ & $p$ \\
\hline \multicolumn{5}{|l|}{ Baseline characteristics } \\
\hline Age (years) & $38.00(31.00-44.00)$ & $36.00(31.00-43.00)$ & $40.00(33.00-45.00)$ & 0.047 \\
\hline Male & 118 (78.67\%) & $66(85.71 \%)$ & $52(71.23 \%)$ & 0.049 \\
\hline BMI $\left(\mathrm{kg} / \mathrm{m}^{2}\right)$ & $26.15(24.20-28.30)$ & $26.00(24.80-28.40)$ & $26.40(24.20-28.30)$ & 0.880 \\
\hline Hypertension & $23(15.33 \%)$ & $10(12.99 \%)$ & $13(17.80 \%)$ & 0.553 \\
\hline Diabetes & $44(29.33 \%)$ & $20(25.97 \%)$ & $24(32.88 \%)$ & 0.454 \\
\hline History of pancreatitis & $59(39.33 \%)$ & $33(45.21 \%)$ & $25(34.25 \%)$ & 0.282 \\
\hline $\mathrm{TG}(\mathrm{mg} / \mathrm{dL})$ & $1760.20(1187.60-2534.30)$ & $1599.10(1140.70-1981.40)$ & $2224.80(1351.30-3291.20)$ & $<0.001$ \\
\hline $\mathrm{TC}(\mathrm{mmol} / \mathrm{L})$ & $12.28(8.83-15.96)$ & & & \\
\hline $\mathrm{HDL}-\mathrm{C}(\mathrm{mmol} / \mathrm{L})$ & $0.97(0.59-2.86)$ & $0.97(0.61-2.37)$ & $0.93(0.58-4.23)$ & 0.347 \\
\hline LDL-C (mmol/L) & $2.86(1.55-5.30)$ & $1.91(1.18-3.31)$ & $4.50(2.13-7.23)$ & $<0.001$ \\
\hline $\mathrm{Ca}(\mathrm{mmol} / \mathrm{L})$ & $2.17(1.98-2.48)$ & $2.24(2.05-2.48)$ & $2.11(1.95-2.59)$ & 0.183 \\
\hline Amylase (U/L) & $202.00(108.20-391.80)$ & $246.00(110.00-373.00)$ & $182.00(84.00-396.00)$ & 0.330 \\
\hline Lipase (U/L) & $627.80(290.30-1513.20)$ & $588.00(288.10-1496.00)$ & $637.00(297.60-1592.00)$ & 0.867 \\
\hline \multicolumn{5}{|l|}{$\begin{array}{l}\text { Severity of hypertriglyceri- } \\
\text { demic pancreatitis }\end{array}$} \\
\hline Balthazar CT grade & & & & $<0.001$ \\
\hline$<D$ & $73(48.67 \%)$ & $48(62.33 \%)$ & $25(34.25 \%)$ & \\
\hline$\geq D$ & $77(51.33 \%)$ & $29(37.66 \%)$ & $48(65.75 \%)$ & \\
\hline Organ function & & & & 0.111 \\
\hline NO & $120(80.00 \%)$ & $66(85.71 \%)$ & 54 (73.97\%) & \\
\hline YES & $30(20.00 \%)$ & $11(14.29 \%)$ & 19 (26.03\%) & \\
\hline Ranson score & & & & 0.396 \\
\hline$<3$ & $130(86.67 \%)$ & 69 (89.61\%) & $61(83.56 \%)$ & \\
\hline$\geq 3$ & 20 (13.33\%) & 8 (10.39\%) & $12(16.44 \%)$ & \\
\hline APACHE II & $7.00(5.00-9.00)$ & $7.00(5.00-9.00)$ & $8.00(6.00-10.00)$ & 0.036 \\
\hline \multicolumn{5}{|l|}{ Treatment } \\
\hline Insulin & $101(67.33 \%)$ & $51(66.23 \%)$ & $50(68.49 \%)$ & 0.904 \\
\hline Heparin & $84(56.00 \%)$ & $43(55.84 \%)$ & $41(56.16 \%)$ & 1 \\
\hline AP-associated death & $4(2.67 \%)$ & $0(0 \%)$ & $4(5.48 \%)$ & 0.054 \\
\hline
\end{tabular}


deaths were associated with AP, including two cases of sudden intraperitoneal hemorrhage, one case of systemic inflammation associated with pancreatitis resulted in multiple organ dysfunction, and one case of peripancreatic infection with septic shock.

\section{Baseline characteristics of total cholesterol subgroup of patients}

As shown in Table 1, patients were categorized into 2 groups based on a TC level of $12.4 \mathrm{mmol} / \mathrm{L}$. Patients in the HTC group were older $(p=0.047)$ and has lower proportion of male $(p=0.049)$. In terms of disease severity assessment, patients in the HTC group had more patients with Balthazar $\mathrm{CT}$ grade $\geq \mathrm{D} \quad(p<0.001)$ and higher APACHE II score $(p=0.036)$. However, there was no significant difference in BMI, proportion of diabetes, HDL-C concentration, calcium level, blood amylase/ lipase level, insulin/heparin therapy and organ dysfunction between the two groups. The AP-associated death in HTC group was higher than that in LTC group (5.48\% vs. $0 \%)$, but there was no statistical difference $(p=0.054)$.

\section{Effects of plasmapheresis on primary outcomes by TC categories}

There was significant difference of PP' curative effect between HTC and LTC groups in reducing TG level to below $500 \mathrm{mg} / \mathrm{dL}$ within $48 \mathrm{~h}$ (Table 2). In patients with TC levels higher than $12.4 \mathrm{mmol} / \mathrm{L}$, PP therapy decreased TGs more effectively (OR: 5.17; 95\% CI: 1.88-14.19, $p=0.001)$; however, in patients with lower TC levels, there was no significant difference in the rate of the primary outcome $(p=0.164)$. After adjusting for age, sex, Balthazar CT grade and APACHE II score, the outcome remained consistent ( $p=0.002$ for HTC group and $p=0.353$ for LTC group). Furthermore, the time course of the lowering of TGs within $72 \mathrm{~h}$ of admission categorized by TC-level groups is depicted in Fig. 1. There was no significant interaction effect between time and the treatment group ( $p=0.459$ for interaction) in the LTC group. However, we did find a significant association between rapidly reduction of TGs and PP therapy $(p<0.001$ for interaction) in the HTC group.

\section{Clinical outcomes of patients by TC categories and treatment group}

The influence of PP to patients' clinical outcome may be modified by TC levels. Accordingly, patients were divided into four groups based on their TC levels and whether they had been treated with PP or not. As shown in Table 3, 61 patients were classified into group 1 (LTC + non-PP), 16 into group $2(\mathrm{LTC}+\mathrm{PP})$, 43 into group 3 (HTC + non-PP), and 30 into group 4 $(\mathrm{HTC}+\mathrm{PP})$. Compared the group 1 and group 3 , patients in group 2 and group 4 had higher effective rate in reducing TGs. And non-PP therapy seems less effective in reducing TGs in patients with $\mathrm{TC}$ level higher than $12.40 \mathrm{mmol} / \mathrm{L}$. Patients with PP treatment had longer hospital stays and higher hospital costs. Deaths only reported in groups 3 and group 4, with 90-day mortality rates of $2.33 \%$ and $10.00 \%$, respectively.

To evaluate whether the TG-lowing effect is affected by baseline TG, patients were categorized into high triglyceride (HTG) /low triglyceride (LTG) groups based on a TG level of $1760 \mathrm{mg} / \mathrm{dl}$ (median value of TG). On the basis of TG grouping, the patients were further divided into LTC + LTG/LTC + HTG/HTC + LTG/HTC + HTG groups according to the level of TC (cutoff: $12.4 \mathrm{mmo} / \mathrm{L}$ ). To explore the curative effect of PP, we itemized each group into subgroups of PP and non-PP. As depicted in Fig. 2, PP was shown to be more effective in reducing TGs below $500 \mathrm{mg} / \mathrm{dL}$ in the LTC+LTG and HTC+HTG groups within $48 \mathrm{~h}$. PP also has the potential in lowering TGs in the HTC+LTG group, although the $p$ value exceeded 0.05. Intriguingly, its seems that patients in LTC/HTG group showed a better reduction of TG by non-PP therapy.

\section{Discussion}

In patients with HLAP, different $\mathrm{TC}$ level can result in different therapeutic effects of TG-lowing treatments in clinical application. To our knowledge, this is the first study to explore the association between TC levels and PP therapy among patients with HLAP.

Previous studies have demonstrated that a higher level of TGs might contribute to more severe pancreatitis

Table 2 Effects of plasmapheresis on primary outcomes by TC categories

\begin{tabular}{|c|c|c|c|c|c|c|}
\hline & \multirow{2}{*}{$\begin{array}{l}\text { Plasmapheresis, event } \\
\text { rate }(\%)^{a}\end{array}$} & \multirow{2}{*}{$\begin{array}{l}\text { Non-plasmapheresis, } \\
\text { event rate }(\%)\end{array}$} & \multicolumn{2}{|l|}{ Crude } & \multicolumn{2}{|c|}{ Multivariable adjusted } \\
\hline & & & OR $(95 \% \mathrm{Cl})$ & $p$ value & OR $(95 \% \mathrm{Cl})$ & $p$ \\
\hline \multicolumn{7}{|l|}{$\mathrm{TC}(\mathrm{mmol} / \mathrm{L})$} \\
\hline$\leq 12.40(n=77)$ & $13(81.25 \%)$ & $38(62.30 \%)$ & $2.62(0.67-10.20)$ & 0.164 & $2.05(0.45-9.40)$ & 0.353 \\
\hline$>12.40(n=73)$ & $20(66.67 \%)$ & $12(27.91 \%)$ & $5.17(1.88-14.19)$ & 0.001 & $5.47(1.84-16.25)$ & 0.002 \\
\hline
\end{tabular}




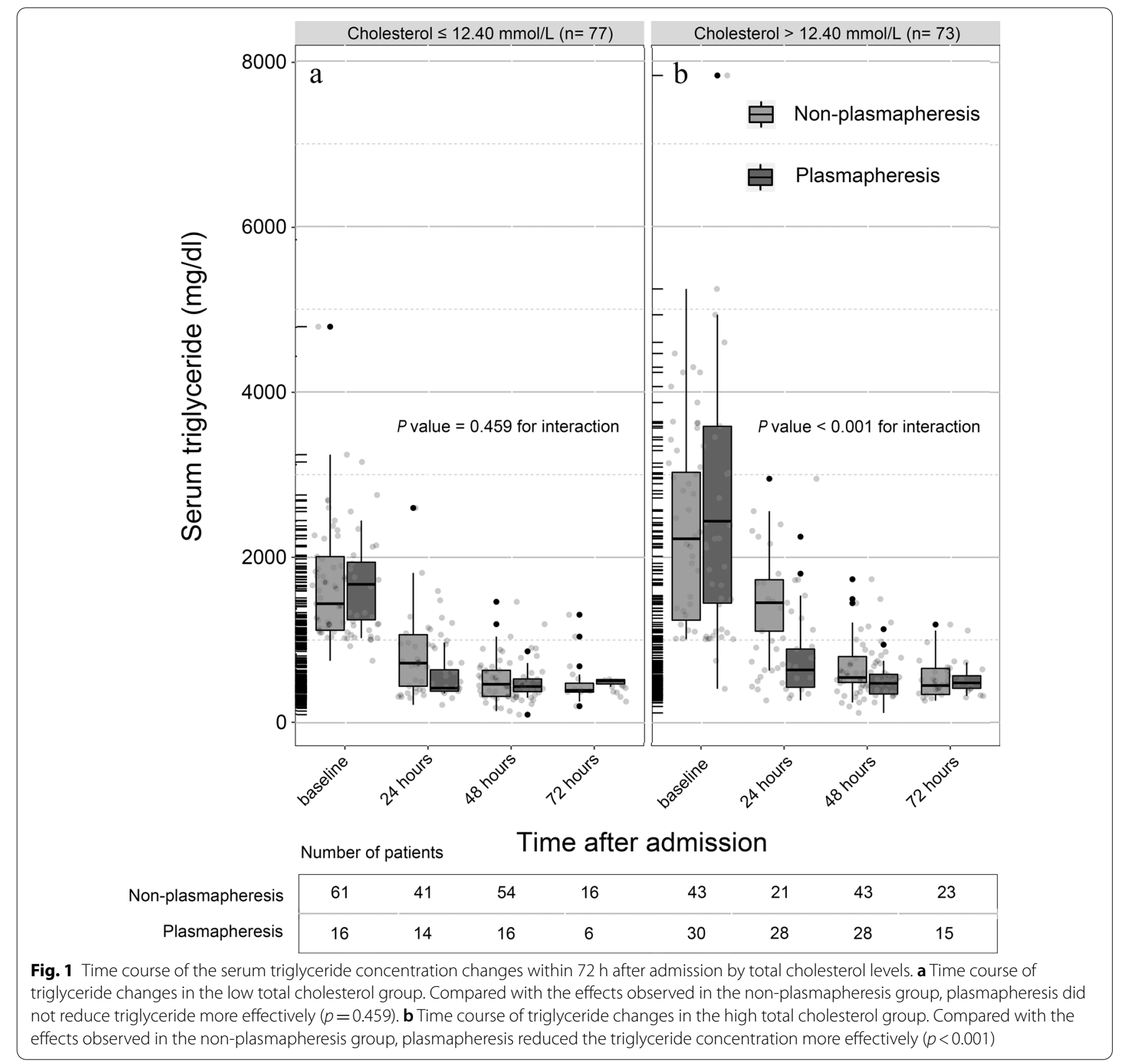

$[17,20,21]$. Reducing TG levels as soon as possible is an important strategy for the treatment of HLAP. PP has traditionally been considered an alternative to TG clearance. In addition, the American Society for Apheresis (ASFA) recommends $\mathrm{PP}$ as an indication for HLAP (grade 2C evidence) [22].

Many studies have shown that high TG levels might be associated with disease progression, and PP should be performed as early as possible when the patient is diagnosed with HLAP $[8,23]$. However, a few previous studies with limited sample sizes have shown that PP was not more effective in reducing TG concentrations [9].
And conservative treatment is effective and safe without PP [24]. Such controversies may be related to the surrogate endpoint, instead of clinical outcomes to evaluate the effect of TG-lowing therapy, in which variability and inconsistence with clinical outcome have been shown.

Until now, what kind of HLAP patients are much more appropriate for PP treatment remains unclear. Early identification of patients suitable for PP is of significant clinical importance [25]. Our study has a relatively large sample size with long time span, which enhances the reliability of the results. In our study, we found that the plasma TC concentration in most patients far exceeded 
Table 3 Clinical outcomes of patients by TC categories and treatment group

\begin{tabular}{|c|c|c|c|c|c|}
\hline & $\begin{array}{l}\text { Group } 1 \\
\text { TC } \leq 12.40 \mathrm{mmol} / \mathrm{L}+\text { non } \\
\operatorname{PP}(n=61)\end{array}$ & $\begin{array}{l}\text { Group } 2 \\
T C \leq 12.40 \mathrm{mmol} / \mathrm{L}+\mathrm{PP} \\
(\mathrm{n}=16)\end{array}$ & $\begin{array}{l}\text { Group } 3 \\
\text { TC }>12.40 \mathrm{mmol} / \mathrm{L}+\text { non } \\
\operatorname{PP}(n=43)\end{array}$ & $\begin{array}{l}\text { Group } 4 \\
\text { TC }>12.40 \mathrm{mmol} / \mathrm{L}+\mathrm{PP} \\
(\mathrm{n}=30)\end{array}$ & $p$ \\
\hline $\mathrm{TG} \leq 500 \mathrm{mg} / \mathrm{dl}$ within $48 \mathrm{~h}$ & $38(62.30 \%)^{\#}$ & $13(81.25 \%)^{\ddagger}$ & $12(27.91 \%)^{\#, \neq, \xi \xi}$ & $20(66.67 \%)^{\xi}$ & $<0.001$ \\
\hline Hospital stay (days) & $8.00(6.00-9.00)^{*,+}$ & $16.00(10.00-21.50)^{*}+, \AA \mathbb{\Omega}$ & $10.00(7.00-12.50)^{\ddagger}$ & $11.00(8.25-16.75)^{t, 9}$ & $<0.001$ \\
\hline $\begin{array}{l}\text { Hospital costs (Yuan in } \\
\text { thousand) }\end{array}$ & $10.92(8.69-14.37)^{*},+$ & $52.55(30.89-91.59)^{*, \neq}$ & $14.75(12.01-21.34)^{\ddagger, \xi}$ & $40.17(35.30-55.88)^{\dagger, \xi}$ & $<0.001$ \\
\hline 28-day mortality & $0(0 \%)$ & $0(0 \%)$ & $1(2.33 \%)$ & $1(3.33 \%)$ & 0.438 \\
\hline 90-day mortality & $0(0 \%)^{\dagger}$ & $0(0 \%)$ & $1(2.33 \%)$ & $3(10.00 \%)^{\dagger}$ & 0.039 \\
\hline
\end{tabular}

* $p<0.05$ for groups 1 versus 2

\# $p<0.05$ for groups 1 versus 3

${ }^{\dagger} p<0.05$ for groups 1 versus 4

₹ $p<0.05$ for groups 2 versus 3

१ $p<0.05$ for groups 2 versus 4

$\xi p<0.05$ for groups 3 versus 4

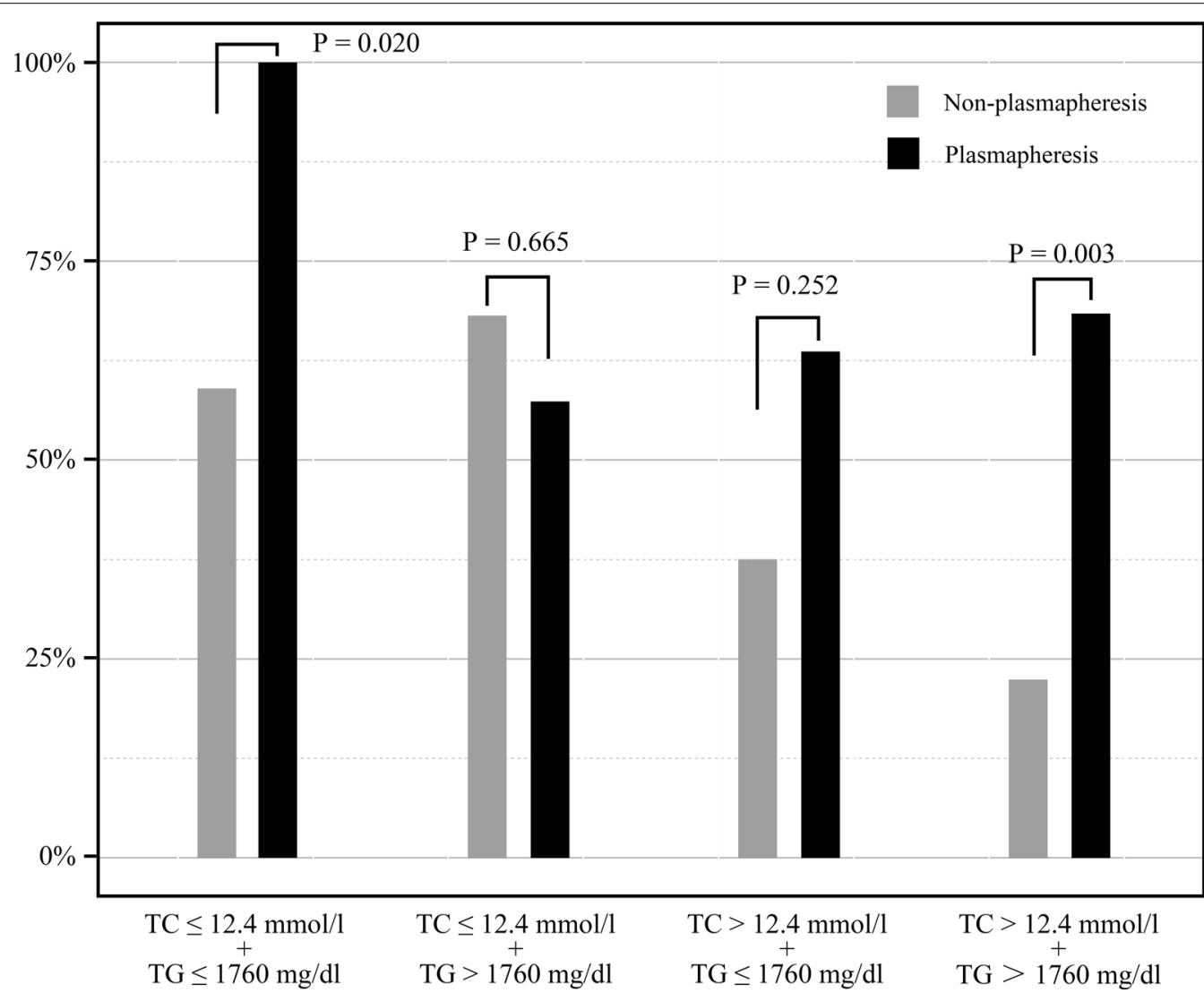

Fig. 2 Effect of plasmapheresis and non-plasmapheresis in different triglyceride and total cholesterol combination groups. TC, total cholesterol; TG, triglyceride

the 'high' limit recommended by the NHLBI. After further grouping by TC concentration, PP showed more efficacy in reducing TGs in the HTC group but not in LTC group. Further considering the impact of baseline TG, patients with HTG and HTC were most suitable for PP treatment, while patients with HTG and LTC were least suitable. Lipid metabolism is dramatically complex and varies from person to person. Common risk factors, such 
as age, gender, insulin/heparin treatment, Balthazar CT grade and severity of illness, are known to interfere with TG-lowing treatment [26]. We have adjusted these factors and found that $\mathrm{TC}$ remained have an independent effect on TG-lowing therapy and the outcomes.

In addition, primary genetic variations among patients are also an important factor of affecting lipid metabolism $[27,28]$. However, it is time-consuming and expensive to perform genetic screening. In contrast, measuring blood biomarkers such as TC level was practical, easy to operate, and economical to predict a patient's response to TG-lowing therapy.

Bile acids are synthesized from TC in the liver and play an important role in the solubilization of lipids in the intestine by acting as biological detergents. Bile acids also affect the absorption of dietary fat, and perturbing bile acid production results in reduced lipid absorption [29]. On the other hand, many enzymes or receptors, such as glycerol-3-phosphate acyltransferase 3, acyl-CoA synthase 5, liver $\mathrm{X}$ receptors and farnesoid $\mathrm{X}$ receptor, are involved in the metabolism of TC and TGs, and there is a mutual feedback regulatory effect [30]. The mutual feedback regulatory mechanism between TC and TGs has not been fully understood, and further research is needed.

Previous studies have shown that the release of systemic inflammatory factors is involved in the occurrence and development of AP [31, 32]. HTC not only leads to a severe inflammatory state, it was an independent risk factor for SAP development [33, 34]. Evidence has unveiled that HTC can lead macrophages and other immune cells to release a large amount of inflammatory factors by enhancing Toll-like receptor (TLR) signaling [35]. The amplification of the inflammatory process can lead to pancreatitis-associated organ injury [36, 37]. Furthermore, through the nuclear transcription factor kappa-B (NF-kB) signaling pathway, HTC can also increase the release of oxygen free radicals, induce lipid peroxidation, damage endothelial cells, and cause further organ dysfunction [32, 38, 39]. Moreover, many animal experiments have shown that HTC can also produce more inflammatory cells by promoting the maturation of the bone marrow and spleen [40]. PP can rapidly remove a variety of inflammatory factors and antibodies, reduce systemic inflammatory reactions and alleviate organ dysfunction [41, 42]. Patients with elevated TC level may benefit from PP therapy. However, it cannot be fooled that PP has the disadvantages of higher costs, longer hospital stays, and more complicated operations.

Our study has several limitations. Firstly, it was a retrospective observational study, the PP group included more severe patients. However, after adjustment for conventional confounding factors, the results remained consistent. Secondly, no gene analysis was performed to determine whether the clinical effects of PP were related to the patient's genotype. Thirdly, cytokine levels were not detected, so the relationship between the efficiency of PP in removing inflammatory cytokines and prognosis was unclear. Until now, whether patients with HLAP can benefit from PP remains unclear, and further randomised controlled trials (RCTs) are needed to evaluate the mortality in the HLAP treated with and without PP. There is an ONGOING RCT study that hopes to help answer this question [43].

\section{Conclusions}

Baseline TC level may predict the effect of conservative treatment or PP therapy on TG-lowing in HLAP patients. TC may also serve as an adjunctive biomarker for clinical selection of patients more suitable for PP.

\section{Abbreviations \\ PP: Plasmapheresis; HLAP: Hypertriglyceridemic acute pancreatitis; TC: Total cholesterol; AP: Acute pancreatitis; TG: Triglyceride; HTG: Hypertriglyceridemia; BMI: Body mass index; HDL-C: High-density lipoprotein cholesterol; LDL-C: Low-density lipoprotein cholesterol; Ca: Calcium; OR: Odd ratios; Cl: Confi- dence interval.}

\section{Acknowledgements}

We thank Ph.D. Jinping Cheng and Ph.D. Xiaoming Rong at Sun Yat-Sen Memorial Hospital, Sun Yat-Sen University (Guangzhou, China) for help with language editing and grammatical errors modification.

\section{Authors' contributions}

ZC: data interpretation and evaluation, manuscript writing. $\mathrm{XH}$ : data collection, analysis and interpretation. $\mathrm{NH}$ : data collection and analysis. YG: data acquisition and analysis. JC: interpretation of data. YN: data collection and revised the manuscript. MZ: study concept and design, manuscript writing and revision. All authors read and approved the final manuscript.

Funding

Not applicable.

\section{Availability of data and materials}

The datasets used and/or analysed during the current study are available from the corresponding author on reasonable request.

\section{Ethics approval and consent to participate}

This study was approved by the Medical Ethics Committee of the First Affiliated Hospital of Xiamen University. Informed consent was waived because the study was conducted retrospectively and no interventions were applied.

\section{Consent for publication}

Not applicable (no details on individuals reported within the manuscript).

\section{Competing interests}

The author(s) declare(s) that they have no competing interests.

\section{Author details}

${ }^{1}$ Intensive Care Unit, The First Affiliated Hospital of Xiamen University, NO. 55, Zhenhai Road, Siming District, Xiamen City, Fujian 361003, People's Republic of China. ${ }^{2}$ Xiamen Blood Center, NO. 121, Hubin South Road, Siming District, Xiamen City, Fujian 361004, People's Republic of China.

Received: 4 June 2020 Accepted: 7 December 2020

Published online: 06 January 2021 


\section{References}

1. Szentesi A, Párniczky A, Vincze Á, Bajor J, Gódi S, Sarlós P, Gede N, Izbéki F, Halász A, Márta K, et al. Multiple hits in acute pancreatitis: components of metabolic syndrome synergize each other's deteriorating effects. Front Physiol. 2019;10:1202

2. Mosztbacher D, Hanák L, Farkas N, Szentesi A, Mikó A, Bajor J, Sarlós P, Czimmer J, Vincze Á, Hegyi PJ, et al. Hypertriglyceridemia-induced acute pancreatitis: a prospective, multicenter, international cohort analysis of 716 acute pancreatitis cases. Pancreatology. 2020:20(4):608-16.

3. Banks PA, Bollen TL, Dervenis C, Gooszen HG, Johnson CD, Sarr MG, Tsiotos GG, Vege SS. Classification of acute pancreatitis-2012: revision of the Atlanta classification and definitions by international consensus. Gut. 2013;62(1):102-11.

4. Tai WP, Lin XC, Liu H, Wang CH, Wu J, Zhang NW, Chen W. A retrospective research of the characteristic of hypertriglyceridemic pancreatitis in Beijing, China. Gastroenterol Res Pract. 2016;2016:6263095.

5. Deng LH, Xue P, Xia Q, Yang XN, Wan MH. Effect of admission hypertriglyceridemia on the episodes of severe acute pancreatitis. World Gastroenterol. 2008;14(28):4558-61.

6. Coskun A, Erkan N, Yakan S, Yildirim M, Carti E, Ucar D, Oymaci E. Treatment of hypertriglyceridemia-induced acute pancreatitis with insulin. Prz Gastroenterol. 2015;10(1):18-22.

7. Kadikoylu G, Yukselen V, Yavasoglu I, Coşkun A, Karaoglu AO, Bolaman Z. Emergent therapy with therapeutic plasma exchange in acute recurrent pancreatitis due to severe hypertriglyceridemia. Transfus Apher Sci. 2010;43(3):285-9

8. Stefanutti C, Labbadia G, Morozzi C. Severe hypertriglyceridemia-related acute pancreatitis. Ther Apher Dial. 2013;17(2):130-7.

9. Miyamoto K, Horibe M, Sanui M, Sasaki M, Sugiyama D, Kato S, Yamashita T, Goto T, Iwasaki E, Shirai K, et al. Plasmapheresis therapy has no triglyceride-lowering effect in patients with hypertriglyceridemic pancreatitis. Intensive Care Med. 2017;43(6):949-51.

10. Click B, Ketchum AM, Turner R, Whitcomb DC, Papachristou Gl, Yadav D. The role of apheresis in hypertriglyceridemia-induced acute pancreatitis: a systematic review. Pancreatology. 2015;15(4):313-20.

11. Gubensek J, Buturovic-Ponikvar J, Romozi K, Ponikvar R. Factors affecting outcome in acute hypertriglyceridemic pancreatitis treated with plasma exchange: an observational cohort study. PLoS ONE. 2014;9(7):e102748.

12. Ewald N, Kloer HU. Treatment options for severe hypertriglyceridemia (SHTG): the role of apheresis. Clin Res Cardiol Suppl. 2012;7(Suppl 1):31-5.

13. Zhou CL, Zhang CH, Zhao XY, Chen SH, Liang HJ, Hu CL, Chen NW. Early prediction of persistent organ failure by serum apolipoprotein $\mathrm{A}-\mathrm{I}$ and high-density lipoprotein cholesterol in patients with acute pancreatitis. Clin Chim Acta. 2018:476:139-45.

14. Zhang Y, Guo F, Li S, Wang F, Meng Z, Zhao J, Liu Z, Wang B, Fan P, Wang $C$, et al. Decreased high density lipoprotein cholesterol is an independent predictor for persistent organ failure, pancreatic necrosis and mortality in acute pancreatitis. Sci Rep. 2017;7(1):8064.

15. Hong W, Lin S, Zippi M, Geng W, Stock S, Zimmer V, Xu C, Zhou M. High-density lipoprotein cholesterol, blood urea nitrogen, and serum creatinine can predict severe acute pancreatitis. Biomed Res Int. 2017;2017:1648385.

16. Working Group IAP/APA Acute Pancreatitis Guideline. IAP/APA evidencebased guidelines for the management of acute pancreatitis. Pancreatology. 2013;13(4 Suppl 2):e1-15.

17. Valdivielso P, Ramírez-Bueno A, Ewald N. Current knowledge of hypertriglyceridemic pancreatitis. Eur J Intern Med. 2014;25(8):689-94.

18. Chatzicostas C, Roussomoustakaki M, Vardas E, Romanos J, Kouroumalis EA. Balthazar computed tomography severity index is superior to Ranson criteria and APACHE II and III scoring systems in predicting acute pancreatitis outcome. J Clin Gastroenterol. 2003;36(3):253-60.

19. Expert Panel on Detection, Evaluation, and Treatment of High Blood Cholesterol in Adults. Executive Summary of The Third Report of The National Cholesterol Education Program (NCEP) Expert Panel on Detection, Evaluation, And Treatment of High Blood Cholesterol In Adults (Adult Treatment Panel III). JAMA. 2001;285(19):2486-97.

20. Vipperla K, Somerville C, Furlan A, Koutroumpakis E, Saul M, Chennat J, Rabinovitz M, Whitcomb DC, Slivka A, Papachristou Gl, et al. Clinical profile and natural course in a large cohort of patients with hypertriglyceridemia and pancreatitis. J Clin Gastroenterol. 2017;51(1):77-85.
21. Wang SH, Chou YC, Shangkuan WC, Wei KY, Pan YH, Lin HC. Relationship between plasma triglyceride level and severity of hypertriglyceridemic pancreatitis. PLoS ONE. 2016;11(10):e163984.

22. Schwartz J, Padmanabhan A, Aqui N, Balogun RA, Connelly-Smith L, Delaney M, Dunbar NM, Witt V, Wu Y, Shaz BH. Guidelines on the use of therapeutic apheresis in clinical practice-evidence-based approach from the writing committee of the american society for apheresis: the seventh special issue. J Clin Apher. 2016;31(3):149-62.

23. Chen JH, Yeh JH, Lai HW, Liao CS. Therapeutic plasma exchange in patients with hyperlipidemic pancreatitis. World J Gastroenterol. 2004;10(15):2272-4.

24. Berberich AJ, Ziada A, Zou GY, Hegele RA. Conservative management in hypertriglyceridemia-associated pancreatitis. J Intern Med. 2019;286(6):644-50.

25. Wu BU, Johannes RS, Sun X, Tabak Y, Conwell DL, Banks PA. The early prediction of mortality in acute pancreatitis: a large population-based study. Gut. 2008;57(12):1698-703.

26. Jain $\mathrm{P}$, Rai RR, Udawat $\mathrm{H}$, Nijhawan $\mathrm{S}$, Mathur A. Insulin and heparin in treatment of hypertriglyceridemia-induced pancreatitis. World J Gastroenterol. 2007:13(18):2642-3.

27. Rodrigues R, Artieda M, Tejedor D, Martínez A, Konstantinova P, Petry H, Meyer C, Corzo D, Sundgreen C, Klor HU, et al. Pathogenic classification of LPL gene variants reported to be associated with LPL deficiency. J Clin Lipidol. 2016;10(2):394-409.

28. Chokshi N, Blumenschein SD, Ahmad Z, Garg A. Genotype-phenotype relationships in patients with type I hyperlipoproteinemia. J Clin Lipidol. 2014:8(3):287-95

29. Paalvast Y, de Boer JF, Groen AK. Developments in intestinal cholesterol transport and triglyceride absorption. Curr Opin Lipidol. 2017;28(3):248-54.

30. Kalaany NY, Mangelsdorf DJ. LXRS and FXR: the yin and yang of cholesterol and fat metabolism. Annu Rev Physiol. 2006;68:159-91.

31. Leung PS, Chan YC. Role of oxidative stress in pancreatic inflammation. Antioxid Redox Signal. 2009;11(1):135-65.

32. Escobar J, Pereda J, Arduini A, Sandoval J, Sabater L, Aparisi L, LópezRodas G, Sastre J. Cross-talk between oxidative stress and pro-inflammatory cytokines in acute pancreatitis: a key role for protein phosphatases. Curr Pharm Des. 2009;15(26):3027-42.

33. Nawaz H, Koutroumpakis E, Easler J, Slivka A, Whitcomb DC, Singh VP, Yadav D, Papachristou Gl. Elevated serum triglycerides are independently associated with persistent organ failure in acute pancreatitis. Am J Gastroenterol. 2015:110(10):1497-503.

34. Hong W, Zimmer V, Basharat Z, Zippi M, Stock S, Geng W, Bao X, Dong J, Pan J, Zhou M. Association of total cholesterol with severe acute pancreatitis: a U-shaped relationship. Clin Nutr. 2020;39(1):250-7.

35. Triantafilou M, Miyake K, Golenbock DT, Triantafilou K. Mediators of innate immune recognition of bacteria concentrate in lipid rafts and facilitate lipopolysaccharide-induced cell activation. J Cell Sci. 2002;115(Pt 12):2603-11.

36. Tall AR, Yvan-Charvet $L$. Cholesterol, inflammation and innate immunity. Nat Rev Immunol. 2015;15(2):104-16.

37. Pastor CM, Pugin J, Kwak B, Chanson M, Mach F, Hadengue A, Frossard JL. Role of Toll-like receptor 4 on pancreatic and pulmonary injury in a mice model of acute pancreatitis associated with endotoxemia. Crit Care Med. 2004;32(8):1759-63.

38. Hermida N, Balligand JL. Low-density lipoprotein-cholesterol-induced endothelial dysfunction and oxidative stress: the role of statins. Antioxid Redox Signal. 2014;20(8):1216-37.

39. Escobar J, Pereda J, López-Rodas G, Sastre J. Redox signaling and histone acetylation in acute pancreatitis. Free Radic Biol Med. 2012;52(5):819-37.

40. Yvan-Charvet L, Pagler T, Gautier EL, Avagyan S, Siry RL, Han S, Welch CL, Wang N, Randolph GJ, Snoeck HW, et al. ATP-binding cassette transporters and HDL suppress hematopoietic stem cell proliferation. Science. 2010:328(5986):1689-93.

41. Kronbichler A, Brezina B, Quintana LF, Jayne DR. Efficacy of plasma exchange and immunoadsorption in systemic lupus erythematosus and antiphospholipid syndrome: a systematic review. Autoimmun Rev. 2016:15(1):38-49.

42. Hatano Y, Katagiri K, Arakawa S, Umeki T, Takayasu S, Fujiwara S. Successful treatment by double-filtration plasmapheresis of a patient with bullous pemphigoid: effects in vivo on transcripts of several genes for 
chemokines and cytokines in peripheral blood mononuclear cells. Br J Dermatol. 2003;148(3):573-9.

43. Zádori N, Gede N, Antal J, Szentesi A, Alizadeh H, Vincze Á, Izbéki F, Papp M, Czakó L, Varga M, et al. EarLy Elimination of Fatty Acids iN hypertriglyceridemia-induced acuTe pancreatitis (ELEFANT trial): Protocol of an open-label, multicenter, adaptive randomized clinical trial. Pancreatology. 2020;20(3):369-76.

\section{Publisher's Note}

Springer Nature remains neutral with regard to jurisdictional claims in published maps and institutional affiliations.
Ready to submit your research? Choose BMC and benefit from:

- fast, convenient online submission

- thorough peer review by experienced researchers in your field

- rapid publication on acceptance

- support for research data, including large and complex data types

- gold Open Access which fosters wider collaboration and increased citations

- maximum visibility for your research: over $100 \mathrm{M}$ website views per year

At BMC, research is always in progress.

Learn more biomedcentral.com/submissions 